\title{
Unusual mixed germ cell testicular carcinoma with pancreatic metastases in a young man
}

\author{
Annia Cavazos MD, Cristina Morataya MD, Gaspar Del Rio-Pertuz MD, Kenneth Iwuji MD
}

\begin{abstract}
$N_{\text {inety-five percent of primary testicular cancers }}$ are germ-cell tumors. Gastrointestinal involvement as a metastasis has a low incidence in a mixed germ cell testicular cancer, especially as an incidental finding at presentation. The incidence of testicular cancer in the United States has increased over the past 20 years. Cryptorchidism has an incidence of $2-5 \%$ of males born at term and is a well-known risk factor for testicular cancer. However, $90 \%$ of persons with testicular cancer do not have a history of cryptorchidism. A few cases of choriocarcinoma involving the pancreas has rarely been reported in the literature. We report a case of incidental pancreatic mass consistent with testicular metastases.
\end{abstract}

A 20-year-old man presented to the outpatient clinic with a recent COVID-19infection with improving symptoms other than anosmia, but he noted cough, nasal drainage, nausea and coffee ground emesis, mid left rib pain secondary to coughing for the past three days, and weight loss. The patient had no previous medical problems, no family history, and no previous surgeries, and he denied tobacco, alcohol, and drug use. During the first medical assessment, patient was found to have an increase in the size of his right testicle. Remarkable laboratory results included a $\beta$-hCG of 742,129 IU/L. A chest x-ray revealed multiple metastatic lesions and hilar adenopathy (Figure 1). A right testicular ultrasound showed a mass (Figure 2). Chest and abdomen computed tomography showed metastatic lung disease to the lung bases (cannonball metastases) and a mass at the head of the pancreas (Figures 3,4). Extensive necrotic tissue

Corresponding author: Annia Cavazos

Contact Information: Annia.Cavazos@ttuhsc.edu

DOI: 10.12746/swrccc.v9i39.843

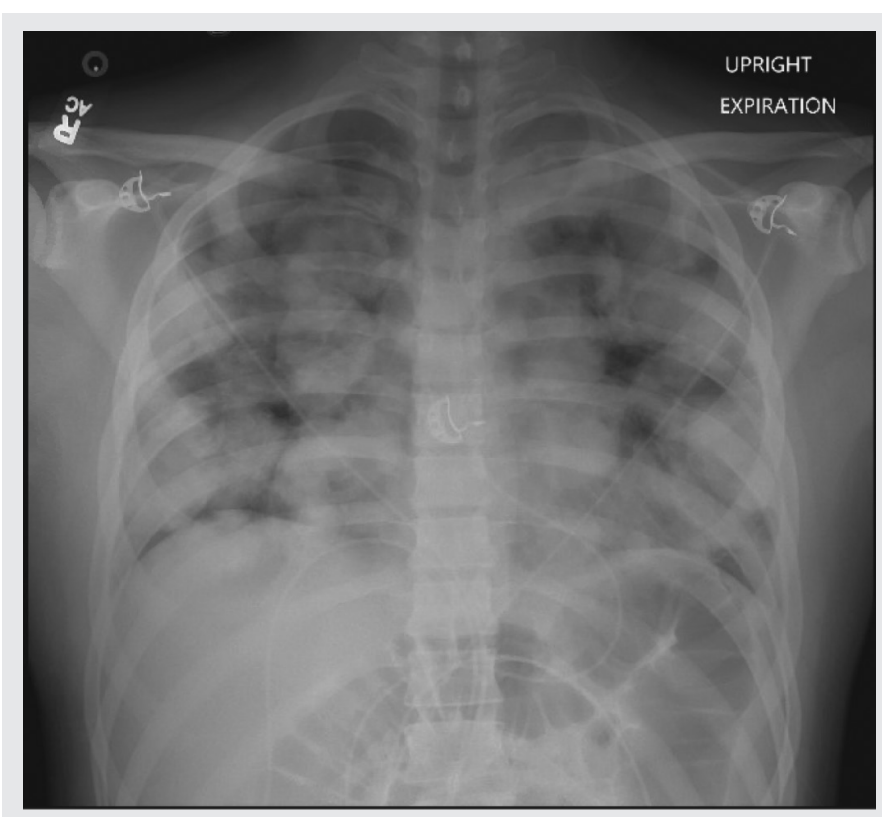

Figure 1. Chest x-ray with multiple metastatic lesions.

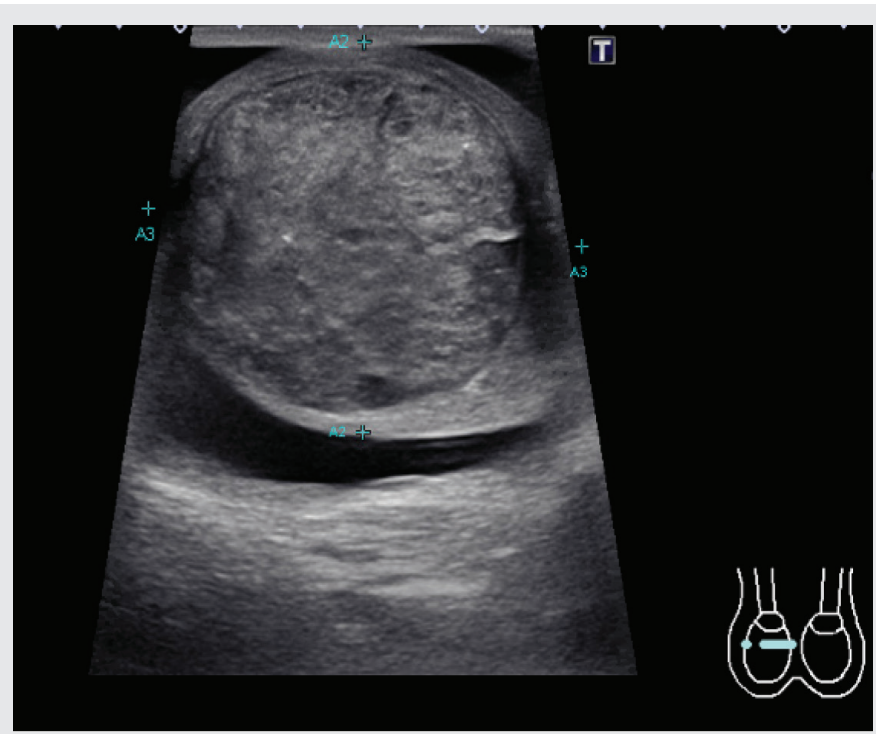

Figure 2. Ultrasound with a right testicular mass. 


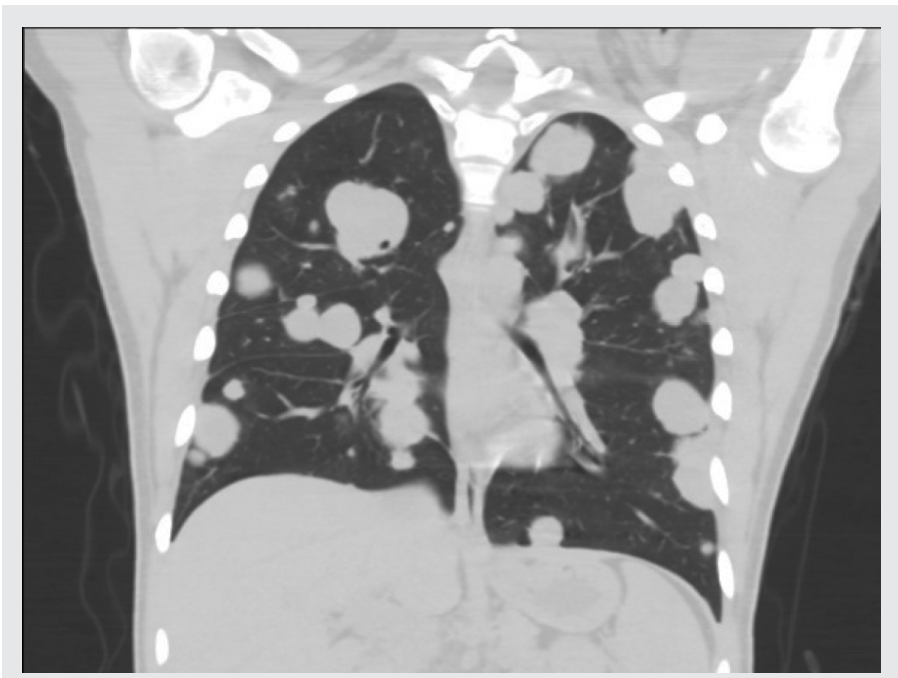

Figure 3. Chest CT with multiple metastasis, so called cannonball metastases.

was reported in the pancreatic and lung biopsies. A right orchiectomy was performed, and final diagnosis for the patient was Stage IV non-seminoma mixed germ cell tumor with $90 \%$ embryonal carcinoma and $10 \%$ choriocarcinoma. He was started on chemotherapy.

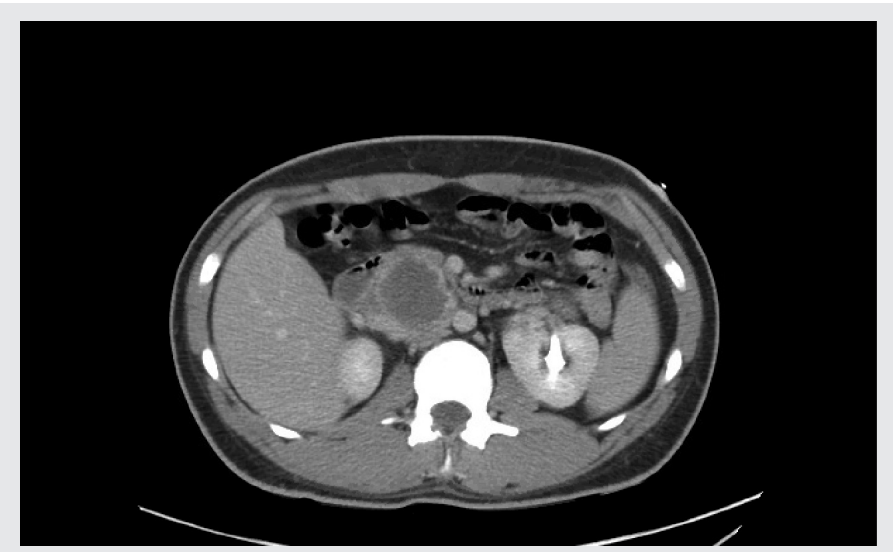

Figure 4. Abdominal CT with a mass of the head of the pancreas.

\section{Discussion}

The incidence of testicular cancer in the USA has continued to increase, most notably in younger and older populations. ${ }^{1}$ Testicular cancer is most commonly diagnosed in stage I presenting as a testicular mass; a small percentage of patients reports back pain or metastatic disease symptoms, such as hemoptysis, cough, pain, and headache. A hypoechoic mass on a testicular ultrasound is diagnostic of testicular cancer. Computed tomography of the chest, abdomen, and pelvis is used for staging. ${ }^{2}$

Choriocarcinoma occurs as a component of a mixed germ cell tumor in $8-10 \%$ of the cases. Fifty percent of the patients will have metastatic disease at the time of presentation. Symptoms are often related to metastases, rather than the testicular tumor. Metastases to the GI tract occur in less than $5 \%$ of the patients. Metastasis to the stomach is the most common, followed by metastasis to the small intestine and colon. ${ }^{3}$

There are very few case reports of testicular cancer metastatic to the pancreas. Gonzalez Garcia and Aldrete reported a case with a cystic pancreatic tumor with a final diagnosis of choriocarcinoma metastatic to the head of the pancreas. ${ }^{4}$ An unusual case of metastatic choriocarcinoma of the pancreas arising from a regressing testicular mixed germ cell tumor without evidence of choriocarcinoma clinically mimicked a primary pancreatic tumor in a 54-year-old man who had progressive upper abdominal pain, weight loss, jaundice, and a history of recurrent epididymitis associated with cystic testicular mass. ${ }^{5}$

To our knowledge, this case is the first case report of a non-seminoma mixed germ cell tumor with $90 \%$ embryonal carcinoma and $10 \%$ choriocarcinoma with an unusual metastatic pancreatic mass found as an incidental finding during the testicular cancer workup, an uncommon clinical presentation. Even though patient presented with respiratory symptoms associated with lung metastasis, an increase in size of a testicle in a young male raised the possibility of testicular cancer. 
Keywords: Metastatic testicular cancer, mixed germ cell tumor, pancreatic metastasis

Article citation: Annia Cavazos A, Morataya C, Gaspar Del Rio-Pertuz G, Iwuji K. Unusual mixed germ cell testicular carcinoma with pancreatic metastases in a young man. The Southwest Respiratory and Critical Care Chronicles 2021;9(39):86-88

From: Department of Internal Medicine, Texas Tech University Health Sciences Center, Lubbock, Texas

Submitted: $1 / 20 / 2021$

Accepted: $2 / 22 / 2021$

Reviewer: Eman Attaya MD

Conflicts of interest: none

This work is licensed under a Creative Commons Attribution-ShareAlike 4.0 International License.

\section{REFERENCES}

1. Nigam M, Aschebrook-Kilfoy B, Shikanov S, et al. Increasing incidence of testicular cancer in the United States and Europe between 1992 and 2009. World J Urol 2015 May;33(5):623-31.

2. Hanna NH, Einhorn LH. Testicular cancer-discoveries and updates. N Engl J Med 2014 Nov 20;371(21):2005-16.

3. Lowe K, Paterson J, Armstrong S, et al. Metastatic testicular choriocarcinoma: a rare cause of upper GI bleeding. ACG Case Rep J 2015;3(1):36-38.

4. González García M, Aldrete JS. Neoplasias quísticas del páncreas: informe de tres casos de difícil diagnóstico [Cystic neoplasms of the pancreas: report of 3 cases presenting diagnostic difficulties]. Rev Invest Clin 1995 Jan-Feb;47(1):43-8.

5. Wang L, Pitman M, Castillo CD, et al. Choriocarcinoma involving the pancreas as first manifestation of a metastatic regressing mixed testicular germ cell tumor. Mod Pathol 2004; 17,1573-1580. 